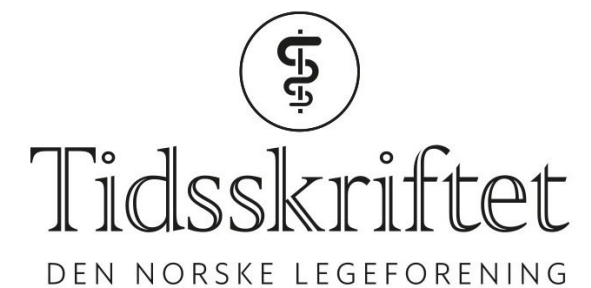

DEN NORSKE LEGEFORENING

\title{
Rekonstruksjon ved facialisparese
}

KLINISK OVERSIKT

\section{HILDE BRUNVOLD BJARKE}

E-post: hilde@cosmoclinic.no

Avdeling for plastikk- og rekonstruktiv kirurgi

Oslo universitetssykehus, Rikshospitalet

Cosmo Clinic

Hun har bidratt til utforming av manus og behandling av den aktuelle pasientgruppen.

Hilde Brunvold Bjærke er spesialist i plastikkirurgi og overlege

Forfatter har fylt ut ICMJE-skjemaet og oppgir ingen interessekonflikter.

\section{THERESE HALVORSEN BJARK}

Avdeling for plastikk- og rekonstruktiv kirurgi

Oslo universitetssykehus, Rikshospitalet

Hun har bidratt til utforming av manus og behandling av den aktuelle pasientgruppen.

Therese Halvorsen Bjark er spesialist i plastikkirurgi og seksjonsoverlege.

Forfatter har fylt ut ICMJE-skjemaet og oppgir ingen interessekonflikter.

\section{THOMAS BERG}

Avdeling for plastikk- og rekonstruktiv kirurgi

Oslo universitetssykehus, Rikshospitalet

Cosmo Clinic

Han har bidratt til utforming av manus og behandling av den aktuelle pasientgruppen.

Thomas Berg er ph.d., spesialist i plastikkirurgi og overlege.

Forfatter har fylt ut ICMJE-skjemaet og oppgir ingen interessekonflikter.

Facialisparese (ansiktslammelse) kan være en stigmatiserende tilstand og kan i mange tilfeller påvirke både lukkefunksjonen av øyet, ansiktsmimikk, nasal luftveispassasje, språk og næringsinntak i ulik grad. For de fleste av pasientene finnes det behandlingsmetoder som kan forbedre funksjon og livskvalitet. Formålet med denne artikkelen er å gi en oversikt over aktuelle kirurgiske rekonstruksjonsmetoder og behandlingsmuligheter for pasienter med facialisparese.

Facialisparese kan være sentral eller perifer og skyldes skade eller sykdom i deler eller hele nervens forløp. Symptomene avhenger av hvilke grener av nerven som er affisert samt graden av nerveskaden. Lammelsen kan være uni- eller bilateral, partiell eller komplett (paralyse), avhengig av hvor kraftig nerven er skadet.

En komplett lammelse medfører hengende munnvik med sikling, utydelig tale og manglende smil. Øyebrynet står lavere og pasientene klarer ikke å lukke øyet (lagoftalmus), med påfølgende risiko for skade på hornhinnen. Ved en facialisparese kan man i tillegg til muskelsvakhet ha plagsomme synkinesier (medbevegelser) og muskelkontrakturer på den affiserte siden (1).

Det er viktig å ikke undervurdere den psykososiale innvirkningen en facialisparese kan 
medføre for denne pasientgruppen, da ansiktsmimikk spiller en viktig rolle i mellommenneskelig kommunikasjon.

Ved Avdeling for plastikk- og rekonstruktiv kirurgi, Oslo universitetssykehus, Rikshospitalet, gjøres det årlig ca.100-120 rekonstruktive inngrep på pasienter med facialisparese. I tillegg utføres det ca. 350-400 polikliniske konsultasjoner hvert år, hvorav ca. 200 polikliniske behandlinger med botulinumtoksin. Det foreligger ikke noe landsfunksjon for pasienter med facialisparese, men de fleste rekonstruktive inngrep blir utført ved Rikshospitalet.

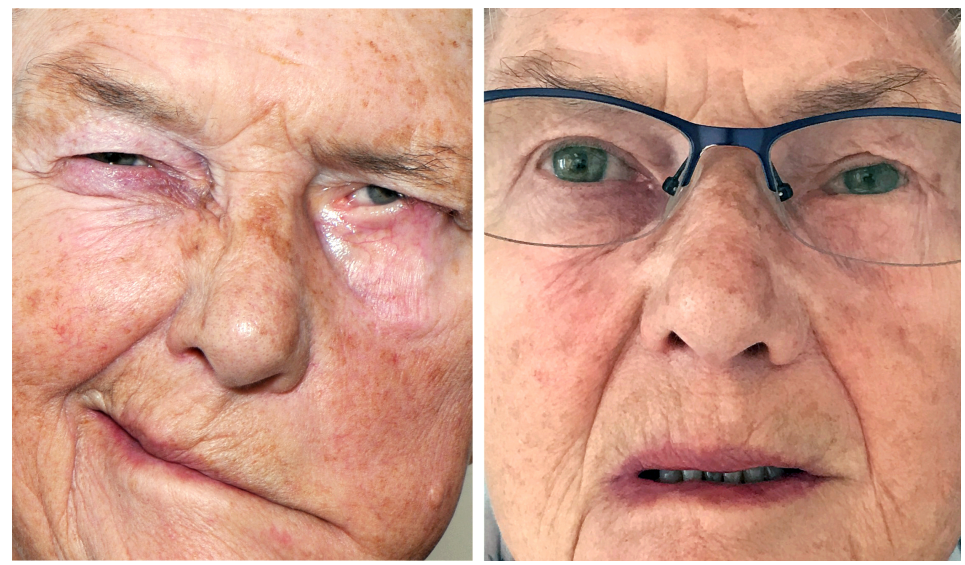

Figur 1 Før og etter operasjon. Dame i 6o-årene med venstresidig komplett facialisparese som har fått utført statisk rekonstruksjon av øye med lateral kantoplastikk, gullvekt, tarsalplatestøtte, åpent øyebrynsløft og statisk korreksjon av munn med fascia lata-slynge.

Det har vært en betydelig utvikling av plastikkirurgiske teknikker for behandling av pasienter med facialisparese de siste tiårene. Vi opplever at disse behandlingsmetodene er lite kjent og at mange pasienter blir henvist sent eller ikke får behandlingstilbud. Vi ønsker derfor å gi en oversikt over aktuelle rekonstruksjonsmetoder. Kunnskapsgrunnlaget for artikkelen er basert på forfatternes kliniske erfaring samt skjønnsmessig litteraturutvalg.

\section{Årsaker og behandling}

Det er mange ulike årsaker til facialisparese. Etiologisk deles tilstanden inn i to hovedgrupper: kongenitte (medfødte) og ervervede (2).

Kongenitte facialispareser er ofte idiopatiske, noen skyldes fødselstraume eller inngår som del av et syndrom (for eksempel Möbius' syndrom) (2).

Ervervede facialispareser er i 70 \% av tilfellene av ukjent årsak, og tilstanden betegnes da som Bells parese (idiopatisk facialisparese). Bells parese er en akutt innsettende ensidig perifer facialisparese med en insidens på 30-40 per 100 ooo innbyggere, noe som tilsvarer 1 500-2 ooo pasienter per år i Norge $(3,4)$. Det foreligger vitenskapelig dokumentasjon fra flere store randomiserte studier at tidlig behandling med kortison $ø$ ker grad av tilheling og at ca. 72-90 \% av pasientene får tilbake normal nervefunksjon (5-7).

De vanligste kjente årsakene til facialisparese er herpes zoster-infeksjon, nevroborreliose, akutt og kronisk ørebetennelse, traume mot nerven samt maligne parotistumorer $(4,8)$. Basert på tall fra epidemiologiske studier fra andre vestlige land, anslås det at 2 100-2 8 oo mennesker får perifer facialisparese av ulike årsaker i Norge hvert år $(3,4)$, men det nøyaktige tallet er ikke kjent. 

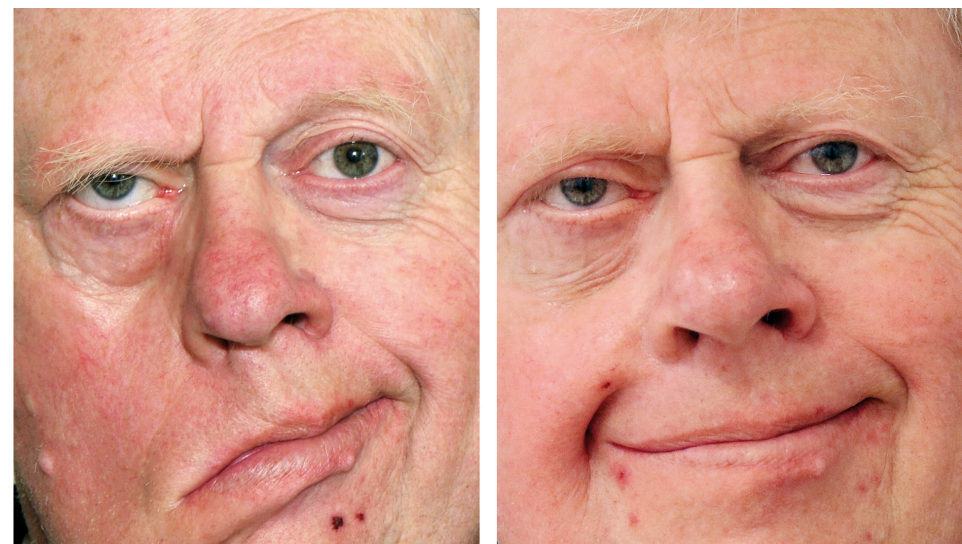

Figur 2 Før og etter operasjon. Mann i 6o-årene med komplett venstresidig facialisparese som har fått utført dynamisk rekonstruksjon til munnen med temporaliselongasjonsplastikk med Labbés metode samt statisk rekonstruksjon av øye med lateral kantoplastikk, gullvekt og tarsalplatestøtte.

Det finnes flere graderingssystemer som brukes til å måle paresens alvorlighetsgrad (9), men det foreligger ikke noen klassifikasjon eller internasjonal enighet om hvilken grad av lammelse som krever rekonstruksjon. Indikasjon for behandling er avhengig av pasientens kliniske bilde, subjektive plager samt komorbiditet. Det er derfor nødvendig å legge en individuell behandlingsplan i hvert enkelt tilfelle.

\section{Primær rekonstruksjon av nerveskade}

Ved ansiktstraume eller kirurgi som medfører deling av nerven, kan man - avhengig av lokalisasjonen og årsaken til skaden - suturere nerven. Det er fordelaktig å operere pasienten innen 72 timer etter skaden, da dette muliggjør identifisering av den distale nerveenden ved bruk av en nervestimulator. Ved tensjon under nervekoblingen eller avstand mellom proksimale og distale nerveende brukes nervetransplantat (10).

\section{Ved permanent facialisparese}

Kirurgisk rekonstruksjon av permanent/kronisk facialisparese deles inn i to hovedgrupper: statiske og dynamiske rekonstruksjoner. De statiske har som mål å gjenopprette symmetri av ansiktet i hvile, mens de dynamiske tilstreber å gjenskape muskelfunksjon til henholdsvis munnen (smilet) og til øyet for å forbedre lukkefunksjon. En vellykket rekonstruksjon er en stor utfordring, og det er ofte nødvendig å ta i bruk flere ulike kirurgiske teknikker for å oppnå et tilfredsstillende resultat (11).

\section{STATISK REKONSTRUKSJON AV ØYET}

Ringmuskelen rundt øyet ( $\mathrm{m}$. orbicularis oculi) gir støtte til nedre øyelokk og sørger for at det ligger inntil øyeeplet, mens øvre halvdel av muskelen har som oppgave å lukke øyet. Ved facialisparese oppheves øyets lukkefunksjon (lagoftalmus), og støtten til nedre øyelokk svekkes (ektropion). Dette gir fare for uttørring av hornhinnen med påfølgende infeksjon. Konservativ behandling med kunstig tårevæske, øyesalve samt å teipe igjen øyet om natten er viktig for å hindre uttørring av øyet i påvente av operasjon eller eventuell bedring av nervefunksjon.

Hovedmålet med øyerekonstruksjonene er å gjenopprette en god beskyttelse av hornhinnen. Det er ofte nødvendig med kombinasjonsinngrep med korreksjon av både øvre og nedre øyelokk for å oppnå et tilfredsstillende resultat med god lukkefunksjon.

For å bedre lukkefunksjonen til øvre øyelokk er implantasjon av gullvekt i øvre øyelokk den vanligste operasjonen. Tyngden av vekten hjelper pasienten med å lukke øyet i oppreist stilling.

For å korrigere ektropion og stramme opp nedre øyelokk kan man bruke flere teknikker, enten enkeltstående eller i kombinasjon. Vårt førstevalg er lateral kantoplastikk, som er en operasjon der vi forkorter og strammer opp nedre øyelokk. Dette utføres ofte i kombinasjon 
med innleggelse av en liten tynn plate (Medpor) under muskelen i nedre øyelokk som gir støtte og stivhet (tarsalplatestøtte) (12).

\section{STATISK REKONSTRUKSION AV MUNNEN}

En facialisparese med hengende munnvik gir både funksjonelle og kosmetiske utfordringer. Pasientene har plager med sikling, matinntak og artikulasjon.

Dersom pasienten ikke er kandidat for en dynamisk reanimasjon av munnen pga. alder, komorbiditet eller annen årsak, kan man tilby statisk korreksjon. Den vanligste statiske korreksjonen av munnen er en såkalt slyngeplastikk, hvor man opererer inn en senebit (f.eks. fascia lata) mellom tinning og munnvik. Munnviken heises opp i ønsket posisjon og munnen blir mer symmetrisk i hvile (13).

\section{ANDRE STATISKE KORREKSJONER}

Pasienter med facialisparese får ofte ptose av øyebrynet på den affiserte siden. Hos enkelte kan øyebrynet sige så langt ned at det gir innskrenket synsfelt. I disse tilfellene er det ofte nødvendig med et øyebrynsløft. Den enkleste teknikken er et åpent øyebrynsløft der man fjerner hud i overkant av øyebrynet og fester brynet i en høyere posisjon. Øyebrynsløft kan også utføres endoskopisk (kikkhullsteknikk) via hårfestet. Øyebrynene og pannen mobiliseres oppover og fikseres med små skruer til skallebenet.

Atrofisk muskulatur i ansiktet fører på sikt til et nedsunket midtansikt. Dette vil igjen ofte forverre pasientens øyeplager, da midtansiktet normalt er med på å gi støtte til det nedre øyelokket. Pasienter med uttalt ektropion har derfor ofte behov for et midtansiktsløft i tillegg til statisk øyerekonstruksjon for å oppnå et tilfredsstillende resultat (14).

I tillegg kan det være nødvendig med andre typer ansiktsinngrep som transplantasjon av fett, ansiktsløft og øyelokksplastikk for å oppnå best mulig symmetri i ansiktet.

\section{DYNAMISK REKONSTRUKSJON}

Ved dynamiske rekonstruksjoner tilføres ny muskulatur med innervasjon for å gi bevegelse av ansiktet. Ansiktsmimikken er et fint samspill mellom over 40 muskler, og på grunn av ansiktsmusklenes kompleksitet er dynamisk rekonstruksjon en stor utfordring. Målet er å skape mest mulig symmetri i ansiktet både i hvile og ved bevegelse. Nedenfor omtales de to vanligste formene for dynamisk rekonstruksjon både ved Oslo universitetssykehus og internasjonalt.

Fri muskeltransplantasjon

Den vanligste metoden for dynamisk rekonstruksjon av «et smil» har i mange år vært crossfacial nervetransplantasjon etterfulgt av fri muskeltransplantasjon utført i to operasjoner (15). Ved den første operasjonen henter man $\mathrm{n}$. suralis fra leggen, kobler denne mot en facialisgren som innerverer smilemuskler på den friske siden, og nerven legges under huden over på paretisk side. Det vokser så ut nye aksoner i nervetransplantatet som fører nerveimpulser over til den syke siden av ansiktet. Når aksonene har nådd enden av nervetransplantatet etter ca. 8-12 måneder, er det klart for muskeltransplantasjon. Flere muskler kan brukes, men $\mathrm{m}$. gracilis fra innsiden av låret er den mest brukte for rekonstruksjon. En del av muskelen, inkludert kar- og nerveforsyning, flyttes opp til den paretiske siden av ansiktet. Muskelnerven kobles mot nervetransplantatet (n. suralis), blodkar kobles med mikrokirurgisk teknikk og muskelen festes fra munnviken og opp mot tinningen. Det tar så ytterligere 6-8 måneder før reinnervasjon av muskelen er fullført. Når pasienten smiler, aktiveres muskelen fra facialisnerven på den friske siden via den crossfaciale nerven. Metoden innebærer to relativt store operasjoner som gir best resultat hos unge. Ved Oslo universitetssykehus brukes metoden derfor mest hos barn med medfødt parese.

Temporaliselongasjonsplastikk

Daniel Labbé introduserte i 1997 en ny teknikk for dynamisk rekonstruksjon av et smil ved 
bruk av temporalismuskelen (16). Dette er en tyggemuskel som innerveres av trigeminusnerven og vanligvis ikke affiseres ved facialisparese. Ved Labbés metode løser man ut hele muskelutspringet fra skallen og deler festet til temporalissenen på underkjeven med fortsatt intakt blodforsyning og nerveinnervasjon. Muskelsenen kan så forflyttes ned til munnviken der den festes. Når pasienten aktiverer temporalismuskelen ved å tygge, vil muskelen kunne løfte munnviken. Fordelen med denne operasjonen er at muskelen er innervert og dermed ikke avhengig av reinnervasjon, slik som ved en fri muskeltransplantasjon (17). Ulempen er at muskelen ikke er emosjonelt styrt av facialisnerven, men aktiveres ved tygging. De fleste pasientene oppnår imidlertid et spontant smil ved hjelp av fysioterapi og trening. Våre erfaringer er at dette er en meget forutsigbar metode som gir en god dynamisk rekonstruksjon. Ved Oslo universitetssykehus har denne operasjonen blitt brukt i økende grad siden 2010 både til barn og voksne, med et meget godt resultat.

\section{Botulinumtoksin}

Ca. $15-30 \%$ av pasientene med perifer facialisparese får synkinesier (medbevegelser) når nerven tilheler (4). Synkinesi er en ufrivillig bevegelse som følge av en abnormal reinnervasjon av nerven. Eksempel på dette er at øyet lukker seg ved smil, kontraksjon av platysma ved ansiktsbevegelser eller tåresekresjon ved spising. I tillegg til synkinesier kan pasienter med facialisparese også ha plagsomme muskelspasmer. Injeksjoner med botulinumtoksin kan dempe synkinesier og muskelspasmer. Dette brukes også for å forbedre symmetri i ansiktet ved å dempe funksjonen i utvalgte muskelgrupper på den friske siden. Effekten varer i ca. 3-4 måneder og må derfor gjentas. Behandlingen kombineres ofte med fysioterapi som har til hensikt å gi pasientene bedre kontroll på ansiktsmuskulaturen.

LITTERATUR:

1. Bylund N, Jensson D, Enghag S et al. Synkinesis in Bell's palsy in a randomised controlled trial. Clin Otolaryngol 2017; 42: 673-8o. [PubMed][CrossRef]

2. May M, Schaitkin BM. The facial nerve. New York, NY: Thieme Medical, 2000.

3. Katusic SK, Beard CM, Wiederholt WC et al. Incidence, clinical features, and prognosis in Bell's palsy, Rochester, Minnesota, 1968-1982. Ann Neurol 1986; 20: 622 - 7. [PubMed][CrossRef]

4. Peitersen E. Bell's palsy: the spontaneous course of 2,50o peripheral facial nerve palsies of different etiologies. Acta Otolaryngol Suppl 2002; 122: 4-30. [PubMed][CrossRef]

5. Engström M, Berg T, Stjernquist-Desatnik A et al. Prednisolone and valaciclovir in Bell's palsy: a randomised, double-blind, placebo-controlled, multicentre trial. Lancet Neurol 20o8; 7: 993 - 1000. [PubMed][CrossRef]

6. Madhok VB, Gagyor I, Daly F et al. Corticosteroids for Bell's palsy (idiopathic facial paralysis). Cochrane Database Syst Rev 2016; 7: CDoo1942. [PubMed]

7. Sullivan FM, Swan IR, Donnan PT et al. Early treatment with prednisolone or acyclovir in Bell's palsy. N Engl J Med 2007; 357: 1598 - 607. [PubMed][CrossRef]

8. Hohman MH, Hadlock TA. Etiology, diagnosis, and management of facial palsy: 2000 patients at a facial nerve center. Laryngoscope 2014; 124: E283 - 93. [PubMed][CrossRef]

9. Fattah AY, Gurusinghe AD, Gavilan J et al. Facial nerve grading instruments: systematic review of the literature and suggestion for uniformity. Plast Reconstr Surg 2015; 135: 569 - 79. [PubMed][CrossRef]

10. Colbert S, Coombes D, Godden D et al. How do I manage an acute injury to the facial nerve? $\mathrm{Br} J$ Oral Maxillofac Surg 2014; 52: 67 - 71. [PubMed][CrossRef]

11. Razfar A, Lee MK, Massry GG et al. Facial paralysis reconstruction. Otolaryngol Clin North Am 2016; 49: 459 - 73. [PubMed][CrossRef] 
12. Sohrab M, Abugo U, Grant M et al. Management of the eye in facial paralysis. Facial Plast Surg 2015; 31: 140 - 4. [PubMed][CrossRef]

13. Leckenby JI, Harrison DH, Grobbelaar AO. Static support in the facial palsy patient: a case series of ${ }_{51}$ patients using tensor fascia lata slings as the sole treatment for correcting the position of the mouth. J Plast Reconstr Aesthet Surg 2014; 67:350 - 7. [PubMed][CrossRef]

14. Graziani C, Panico C, Botti G et al. Subperiosteal midface lift: its role in static lower eyelid reconstruction after chronic facial nerve palsy. Orbit 2011;30: 140 - 4. [PubMed][CrossRef]

15. Azizzadeh B, Pettijohn KJ. The gracilis free flap. Facial Plast Surg Clin North Am 2016; 24: 47 - 60. [PubMed][CrossRef]

16. Labbé D. Myoplastie d'allongement du temporal et réanimation des lèvres. Note technique. Ann Chir Plast Esthet 1997; 42: 44 - 7. [PubMed]

17. Bos R, Reddy SG, Mommaerts MY. Lengthening temporalis myoplasty versus free muscle transfer with the gracilis flap for long-standing facial paralysis: A systematic review of outcomes. J

Craniomaxillofac Surg 2016; 44: 940 - 51. [PubMed][CrossRef]

Publisert: 5. november 2018. Tidsskr Nor Legeforen. DOI: 10.4045/tidsskr.17.1023

Mottatt 20.11.2017, første revisjon innsendt 6.6.2018, godkjent 27.8.2018.

(C) Tidsskrift for Den norske legeforening 2020. Lastet ned fra tidsskriftet.no 